\title{
Pediatric seatbelt injuries: diagnosis and treatment of lumbar flexion-distraction injuries
}

\author{
T A Greenwald $\mathrm{MD}^{1}$ \& D C Mann MD 2 \\ ${ }^{1}$ Orthopedic Surgery Resident, ${ }^{2}$ Assistant Professor of Orthopedic Surgery, University of \\ Wisconsin Medical School, Madison, Wisconsin, USA.
}

\begin{abstract}
Motor vehicle accidents are the major cause of flexion-distraction injuries of the thoracolumbar spine. In a retrospective review, we present the results of operative treatment for six pediatric patients who sustained such injuries while wearing seatbelts. There were three purely ligamentous injuries, two bony injuries (Chance fractures), and one combination injury. There were also concomitant neurological and intra-abdominal injuries. Of note is that two patients had either their spinal or abdominal injury missed on initial evaluation. All patients were treated surgically with open reduction and internal fixation. At average follow up of 2 years, all patients had a full range of motion with no back pain. Five had returned to their preinjury activity levels, while the sixth patient was paraplegic from his injury but was able to ambulate at home with crutches and knee-ankle-foot orthoses. We recommend operative reduction and two-level fusion of these injuries when (1) instability is apparent in either a purely ligamentous injury or an overtly unstable fracture-pattern, (2) significant kyphosis is present which cannot be reduced or maintained in a cast, or (3) there is associated neurological or intra-abdominal injury.
\end{abstract}

Keywords: pediatric seatbelt injuries; lumbar flexion-distraction injuries; thoracolumbar spine.

\section{Introduction}

Although morbidity and mortality from motor vehicle accidents (MVAs) have been reduced because of increased seatbelt use ${ }^{1-8}$ MVAs are the major cause of over $75 \%$ of flexion-distraction injuries of the thoracolumbar spine..$^{9,10}$ These seatbelt injuries are a result of hyperflexion of the spine about a fixed point anterior to the vertebral body axis. ${ }^{11-22}$

To date, however, no reports have detailed the clinical outcome of pediatric patients who underwent operative treatment for these injuries. We present six cases in which such flexion-distraction injuries of the lumbar spine were treated by surgery, and make recommendations regarding evaluation and treatment.

Correspondence: David C Mann MD, Division of Orthopedic Surgery, 600 Highland Avenue, Madison, WI 53792, USA

\section{Materials and methods}

We reviewed the medical records and radiographs of children who had sustained spinal trauma and were treated at the University of Wisconsin Hospital over a 5-year period (1985-90), and identified six children who underwent operative treatment for flexiondistraction injuries of the lumbar spine sustained while wearing seatbelts during MVAs.

Patients and their parents were interviewed to record vehicles involved and type of accident, patient's position in the car and type of seatbelt worn. Type of injury and degree of kyphosis were determined from preoperative radiographs and computed tomography (CT). Other injuries, in particular concomitant intra-abdominal trauma, were noted. Method of reduction, instrumentation used, and type of fusion performed were obtained from the operative reports. Quality of fusion and degree of 
lordosis were determined from postoperative radiographs, including flexionextension lateral views.

Patient follow up included a complete orthopedic history and physical examination. A neurological examination was also conducted when appropriate.

\section{Results}

Patients

There were four male and two female patients. Average age at time of injury was 8 years and 1 month. All were involved in a high speed (>50 MPH) MVA in which the vehicle struck another vehicle head-on (three), broadside (two), or struck a utility pole (one). Four patients were restrained in the back seat by a lap belt only. Two patients were seated in the front passenger seat wearing a three-point restraint. One, however, was wearing the restraint with the shoulder strap tucked behind his torso, thereby effectively acting as a lap belt only. Pertinent clinical information is summarized in Table I.

\section{Orthopedic injuries}

Three patients had purely ligamentous injuries which were considered unstable (Figs 1a, b). Two patients had bony injuries (Chance fracture) (Figs 2a, b). One patient had a two-level injury with a bony Chance fracture at one level and a purely ligamentous injury at the level below. The level of injury was L1-2 in one patient, L2-3 in two patients, and L3-4 in two patients. The two-level injury involved levels L2-3 and L3-4. All patients had CTs of the spine and only one showed a facet fracture. There were no burst injuries of the vertebral body. Preoperative kyphosis ranged from $5^{\circ}$ to $28^{\circ}$, with an average of $18^{\circ}$.

\section{Neurological injuries}

Two patients had associated neurological injuries. The patient with the two-level injury sustained a severe injury to his cauda equina with resultant paraplegia at L3 level. At the time of surgery, severance of multiple nerve roots was found at the site of the L3-4 bilateral facet dislocation and the

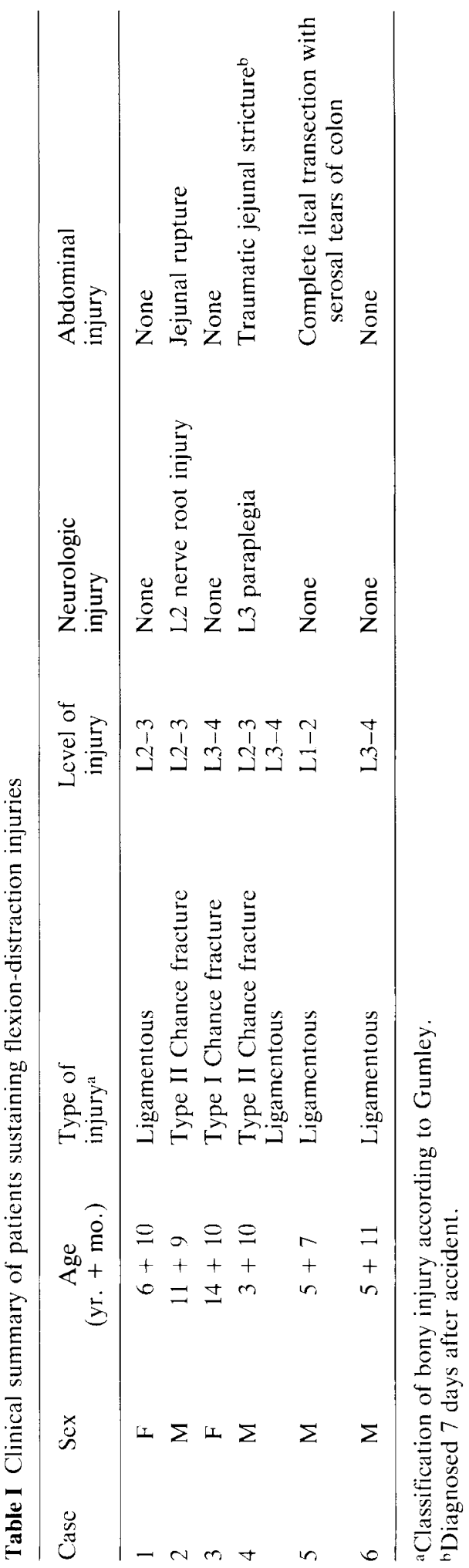


Table II Abdominal and orthopedic management

\begin{tabular}{|c|c|c|c|c|c|}
\hline Case & Abdominal management & $\begin{array}{l}\text { Tme until } \\
\text { surgery }\end{array}$ & Orthopedic management & Bone graft $^{\mathrm{a}}$ & Kyphosis $^{c}$ \\
\hline 1 & Negative abdominal CT & 2 days & 2 sublaminar wires at $\mathrm{L} 2-3$ & Local & $20^{\circ} \mathrm{K} / 9^{\circ} \mathrm{L} / 8^{\circ} \mathrm{L}$ \\
\hline 2 & Jejunal resection & 26 days $^{b}$ & $\begin{array}{l}1 \text { Harrington compression rod at } \mathrm{L} 2-3 \\
\text { with nerve root decompression }\end{array}$ & Left ICBG & $20^{\circ} \mathrm{K} / 4^{\circ} \mathrm{L} / 2^{\circ} \mathrm{L}$ \\
\hline 3 & Negative physical examination & 3 days & $\begin{array}{l}\text { Bilateral Harrington compression rods } \\
\text { at L3-4 }\end{array}$ & Left ICBG & $18^{\circ} \mathrm{K} / 10^{\circ} \mathrm{L} / 6^{\circ} \mathrm{L}$ \\
\hline 4 & Jejunostomy & 1 day & Interspinous processes suturing L2-S1 & None & $19^{\circ} \mathrm{K} / 3^{\circ} \mathrm{L} / 3^{\circ} \mathrm{L}$ \\
\hline 5 & $\begin{array}{l}\text { Ileal resection and transverse colon } \\
\text { resection }\end{array}$ & 9 days & $\begin{array}{l}\text { Halifax clamps with spinous process } \\
\text { wiring at } \mathrm{L} 1-2\end{array}$ & Allo & $28^{\circ} \mathrm{K} / 4^{\circ} \mathrm{L} / 4^{\circ} \mathrm{L}$ \\
\hline 6 & Negative abdominal CT & 3 days & 1 sublaminar wire at $\mathrm{L} 3-4$ & Local & $5^{\circ} \mathrm{K} / 4^{\circ} \mathrm{L} / 3^{\circ} \mathrm{L}$ \\
\hline
\end{tabular}

\section{a Bonegraft \\ Local-using spinous processes \\ ICBG - autologous iliac crest}

Allo-banked cancellous graft.

bSpinal injury initially not diagnosed.

-Preoperative/postoperative/follow up

$\mathrm{K}=$ Kyphosis

$\mathrm{L}=$ Lordosis 
Table III Follow up results

\begin{tabular}{llc}
\hline Case & $\begin{array}{l}\text { Clinical } \\
\text { results }^{\mathrm{a}}\end{array}$ & $\begin{array}{c}\text { Total } \\
\text { follow up } \\
\text { (months) }\end{array}$ \\
\hline 1 & Excellent & 21 \\
2 & Excellent & 12 \\
3 & Excellent & 63 \\
4 & NA $^{\mathrm{b}}$ & 12 \\
5 & Excellent & 16 \\
6 & Excellent & 32 \\
\hline
\end{tabular}

${ }^{a}$ Excellent $=$ no pain, full range of movement (ROM), and full activity.

${ }^{b}$ Patient with paraplegia resulting from MVA.

patient had complete loss of sensation and motor function below this level. The second patient presented with right anterior thigh pain and numbness, and $4+/ 5+$ hip flexor weakness secondary to L 2 nerve root injury. The remaining patients had normal neurological examinations. No patient sustained a major head injury.

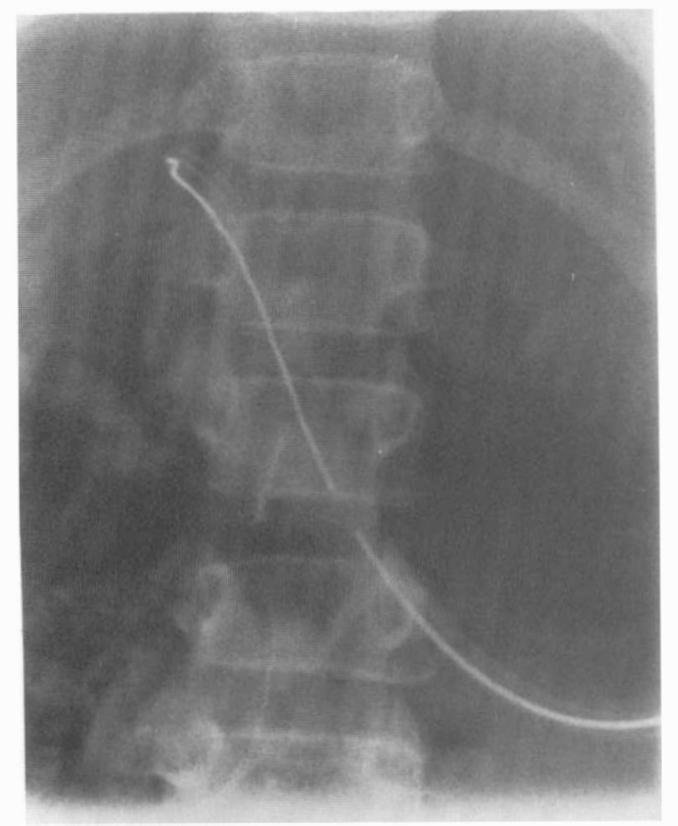

Abdominal injuries (Table II)

All of the patients had abdominal bruising and abrasions consistent with a 'seatbelt sign' (Fig 3), and five complained of abdominal pain upon admission. Three of these patients had major intra-abdominal injuries, requiring exploratory laparotomy with some form of bowel resection and re-anastamosis.

One patient's original abdominal CT was interpreted as negative and, as a result, his abdominal injury was not diagnosed until 7 days after his original trauma. Another patient, who was initially treated at another hospital for his abdominal injury, did not have his spinal injury diagnosed until 3 weeks after his accident.

\section{Orthopedic management (Table II)}

All patients were treated surgically with open reduction and internal fixation. Five underwent surgery within an average of 3 days of their injury. The sixth patient, whose spinal injury was initially missed, had surgery 26 days after his accident. There were no major operative complications.

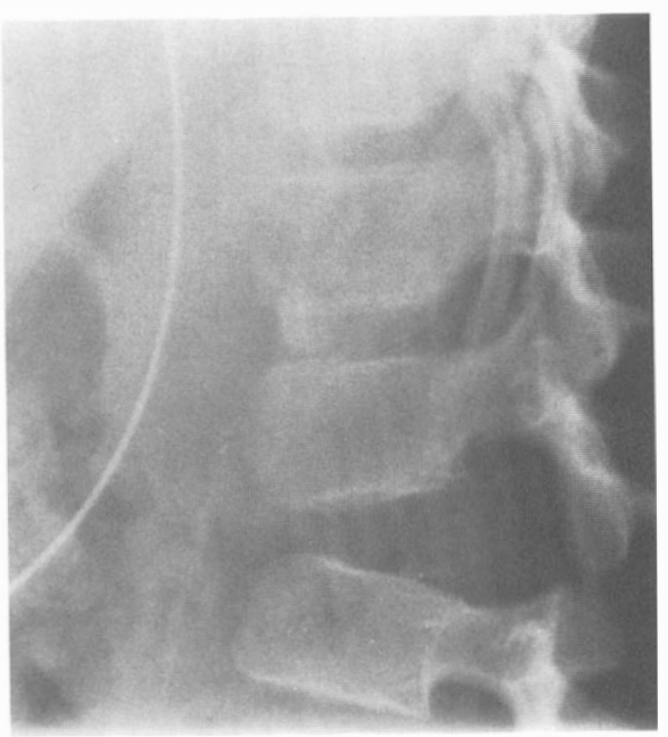

Figure 1 Ligamentous seatbelt injury in case 1. AP radiograph (a) reveals no apparent bony injury, with obvious widening between L2 and L3. Lateral view (b) demonstrates L2-3 flexion-distraction injury without apparent bony injury. Kyphosis was $20^{\circ}$. 


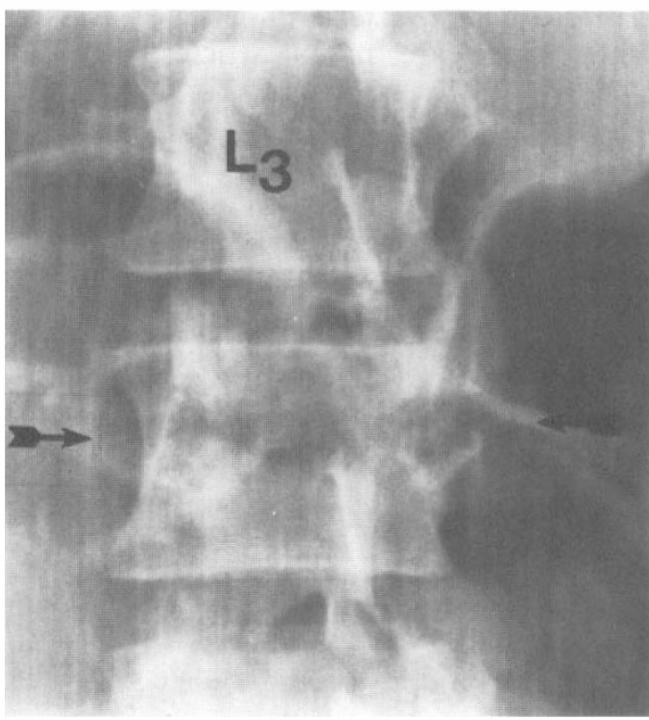

$\mathbf{b}$

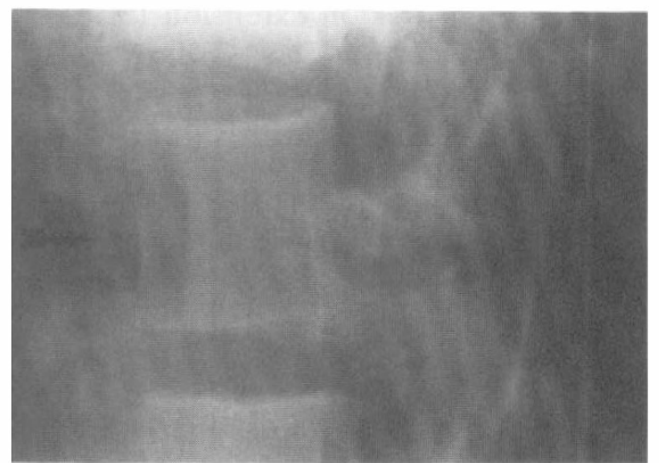

Figure 2 Seatbelt injury in case 3. AP radiograph (a) indicates fracture (arrows) through L4. Lateral view (b) (arrow) shows type I Chance fracture.

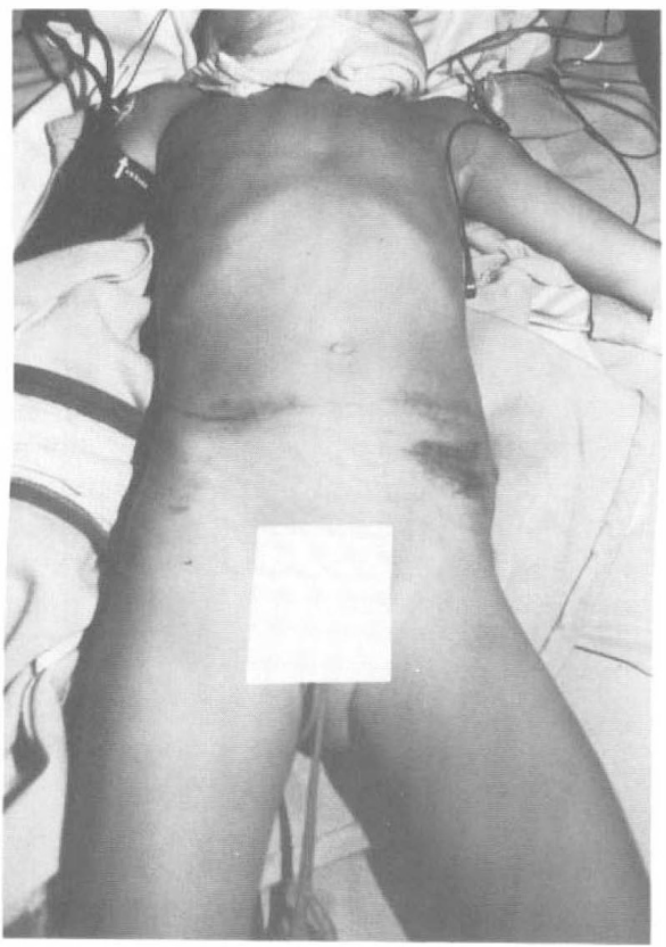

Figure 3 'Seatbelt sign'-abdominal bruising and abrasions at level where lap belt restrained passenger.
Two-level posterior spinal fusion with two-level instrumentation was performed in five patients. Sublaminar wires were used in two patients, Harrington compression rods in two, and Halifax clamps in one patient. Local bone graft was used in two patients, iliac crest bone graft in two, and allograft cancellous bone graft in one patient.

Decompression was performed at surgery on the patient with L2 nerve root injury. Stabilization for the patient with the twolevel injury was accomplished by interspinous process fixation from L2 to S1 with heavy non-absorbable suture. Spinal fusion with bone graft was not performed in consideration of his young age (less than 4 years old) and the multiple levels involved.

Excluding the paraplegic patient, the average postoperative hospital stay was 6 days. All wore a TLSO for 10-12 weeks postoperatively. The paraplegic patient wore a thoraco-lumbar-sacral orthosis (TLSO) with his knee-ankle-foot othoses (KAFOs) attached for 3 months.

\section{Operative outcome (Table III)}

On follow-up radiographs, the five posterior spinal fusions appeared solid with intact 
hardware, and flexion/extension lateral radiographs showed no signs of instability. Flexion/extension radiographs at 1-year follow up on the paraplegic patient revealed maintenance of reduction and no demonstrable instability.

Kyphotic deformity was corrected an average of $22^{\circ}$, resulting in restoration of lumbar lordosis to an average of $4^{\circ}$. Lordosis remained an average of $3^{\circ}$ at final follow up (an average of 2 years postoperatively).

At the time of final follow up, all patients, with the obvious exception of the paraplegic patient, had excellent outcomes. All had a functional range of motion of the spine with regard to flexion/extension and lateral bending and twisting. All spines were nontender and no patient complained of back pain. Five were able to function at their preinjury level. Four were able to participate in competitive athletics after their injuries.

At the 12-months follow up, there was no improvement in the neurological status of the paraplegic patient as he continued to have motor and sensory loss at the L3-4 level. However, he had no back pain and was able to ambulate in his house with crutches and KAFOs, using a swing-through gait.

The patient treated for the L2 nerve root injury had no demonstrable motor deficit 1 year after surgery and had recovered full strength of his hip flexors. He continued to have mildly decreased sensation in his right mid-anterior thigh (L2 paresthesia) but described it as only a mild nuisance.

\section{Discussion}

\section{Pathomechanism of Chance fracture}

Howland et $a l^{23}$ reported on a patient injured while wearing a lap belt, who sustained what they called a 'Chance fracture'. They explained the mechanism of injury as similar to breaking a stick across one's knee, as the lap belt acted as a fixed point around which the patient's spine hyperflexed. Smith \& Kaufer further elucidated the principle pathomechanism of these injuries as a distraction of the posterior spinal elements during hyperflexion around a lap belt. ${ }^{24}$

\section{Previous pediatric series}

While there are many articles regarding seatbelt injuries, relatively few specifically address the issue of these injuries and pediatric patients. Those that deal with pediatric seatbelt injuries consist mainly of case reports ${ }^{25-28}$ or small series with incomplete detailing of orthopedic treatment and follow up..$^{29,30}$

\section{Associated intra-abdominal injuries}

The association of intra-abdominal injuries with flexion-distraction spinal injuries was first recognized by Garrett \& Braunstein ${ }^{31}$ when they described the 'seatbelt syndrome'. Up to $80 \%$ of patients with flexiondistraction injuries of the spine caused by seatbelts have been found to have concomitant major intra-abdominal injuries. Hollow viscus injuries are the most common, especially when passengers wear lap belts and are seated in the rear seat. ${ }^{32}$

Argan reported that the majority of abdominal injuries from lap belt use occurred in children between the ages of 4 and $9 .{ }^{9}$ This is thought to be due to differences in pediatric anatomy, including an increased head-to-body ratio with a more cephalad center of gravity causing increased torque about the axis of rotation.

In addition, the relatively underdeveloped pelvis makes for an improper fit of the lap belt, which could allow the child to 'submarine' under the lap belt. ${ }^{3,29}$ Rather than the deceleration force of the upper body being dissipated by rotation about the hip joint, the lap belt rides above the iliac crests and over the abdomen, concentrating most of the force at the level of the upper lumbar spine with intra-abdominal injuries involving a similar level..$^{10,29,33}$

\section{Missing concomitant injuries}

Of note is that in two of our patients with concomitant intra-abdominal and spinal injuries, one of the injuries was initially missed. This is not an uncommon occurrence. Previous reports have described both delay in the diagnosis of abdominal pathology in patients with known spinal injuries, 
as well as failure to initially recognize spinal injuries in patients with known abdominal trauma. ${ }^{34,35}$

\section{Treatment choices for flexion-distraction injuries}

Treatment of flexion-distraction injuries of the lumbar spine depends most notably on the perceived stability of the injury. Many regard the Chance fracture as stable in extension and have, therefore, treated these injuries non-operatively (usually with casting in extension). ${ }^{24-26,30,33,35-37}$

Gumley et $a l^{33}$ treated 13 out of 20 patients with bony injuries with bed rest and extension casting for 6-8 weeks. Ten patients had good results, whereas two had residual kyphosis of $5^{\circ}$ and one had asymptomatic non-union of the posterior elements. Seven patients were considered to have unstable injuries (including those with significant neurological damage) and were treated with open reduction and posterior spinal fusion. A variety of methods was used and these patients generally did well, especially those that had Harrington compression instrumentation.

LeGay et $a l^{35}$ recommended surgical treatment for ligamentous injuries which did not involve bone, especially when facet joints were disrupted and subluxated. Poor prognosticators for non-operative treatment were facet joint fracture involvement and initial kyphosis greater than $17^{\circ}$.

$\mathrm{Yu} \& \mathrm{Siu}^{37}$ reported on 26 patients with injuries of the lumbar spine while wearing a seatbelt. Of the 22 patients with bony injuries, 16 patients were treated nonoperatively with postural reduction and hyperextension casting. At follow up, six patients had significant angulation (three greater than $20^{\circ}$ and three greater than $30^{\circ}$ ). The authors believed that even though most of the patients with significant angulation were asymptomatic, the loss of normal lumbar lordosis was undesirable as it could lead to significant mechanical low back pain in the future, and recommended open reduction and internal fixation if reduction could not be obtained with postural reduction or maintained with hyperextension casting.

The incidence of neurological injury reported in large series is $11 \%$ $44 \%{ }^{24,29-31,33,35,37-40}$ Approximately half are minor injuries (usually nerve root lesions) and half are major injuries (usually paraplegia). As in our series, patients with minor neurological injuries usually improved. There has been no documented improvement of major neurological injuries after surgical treatment.

\section{Conclusions}

Although there have been some favorable results from non-operative treatment of flexion-distraction injuries, ${ }^{25,26,30,33,37}$ we prefer operative treatment for most of these injuries. We advocate short segment compression rodding, utilizing a pediatric-size rod and hook construct. We would now avoid sublaminar wires.

When injury is limited mainly to the bony elements, there may be less need for surgical intervention. However, we agree with Gertzbein \& Court-Brown ${ }^{38,39}$ that operative treatment avoids the morbidity associated with prolonged bed rest and body casting, and helps to mobilize the patient at an earlier stage. This is especially beneficial for patients requiring surgery for intraabdominal injuries.

We recommend operative treatment of seatbelt injuries when (1) instability is apparent, with either a purely ligamentous injury or an overtly unstable fracturepattern, (2) significant kyphosis is present and adequate reduction cannot be obtained or maintained in a cast (as this loss of normal lumbar lordosis could lead to mechanical low back pain in the future), (3) there is an abdominal injury requiring surgery, and the patient may benefit from early mobilization and is not a suitable candidate for cast wear, or (4) there is a neurological injury (as often some recovery in function may be obtained and rehabilitation is facilitated).

\section{Acknowledgement}

The authors thank Daniel Faber for his editorial assistance in the preparation of this manuscript. 


\section{References}

1 Campbell BJ (1987) Safety belt injury reduction related to crash severity and front seat position. J Trauma 27: $733-739$.

2 Evans L (1986) The effectiveness of safety belts in preventing fatalities. Accid Anal Prev 18: $229-241$.

3 Evans L (1988) Rear seat restraint system effectiveness in preventing fatalities. Accid Anal Prev 20: $129-136$.

4 Johannessen HG (1984) Historical perspective on seat belt restraint systems, No. 840392. In Advances in Belt Restraint Systems: Design, Performance, and Usage, P-141. Warrendale, PA, Society of Automotive Engineers, Inc., February: 217-225.

5 Newman RJ (1989) Complications of seat belt use. Complications Orthop. July/August: 103-108.

6 Sleet DA (1987) Motor vehicle trauma and safety belt use in the context of public health priorities. J Trauma 27: 695-702.

7 Watson N (1983) Road traffic accidents, spinal injuries and seat belts. Paraplegia 21: 63-64.

8 Williams JS, Kirkpatrick JR (1971) The nature of seat belt injuries. J Trauma 11: 207-218.

9 Argan PF, Dunkle DE, Winn AG (1987) Injuries to a sample of seatbelted children evaluated in a hospital emergency room. J Trauma 27: 58-64.

10 Holt BW (1976) Spines and seat belts: mechanisms of spinal injury in motor vehicle crashes. Med J Aust 2: $411-413$.

11 Friedman MM, Becker L, Reichmister JP, Neviaser JS (1969) Seat belt spinal fractures. Am Surg 35: $617-618$.

12 Greenbaum E, Harris L, Halloran WX (1970) Flexion fracture of the lumbar spine due to lap-type seat belts. West $J$ Med 133: 74-76.

13 Haddad GH, Zickel RE (1967) Intestinal perforation and fracture of lumbar vertebra caused by lap-type seat belt. N Y State J Med 1: 930-932.

14 Hudson I, Kavanagh TG (1983) Duodenal transection and vertebral injury occurring in combination in a patient wearing a seat belt. Injury 15: 6-9.

15 Mann DC (1990) Spine fractures in children and adolescents. In: Spine: State of the Art Reviews 4: 25-47.

16 Newman KD, Bowman LM, Eichelberger MR et al (1990) The lap belt complex: intestinal and lumbar spine injury in children. J Trauma 30: 1133-1138.

17 Ritchie WP, Ersek RA, Bunch WL, Simmons RL (1970) Combined visceral and vertebral injuries from lap type seat belts. Surg Gynecol Obstet September: 431-435.

18 Rogers LF (1971) The roentgenographic appearance of transverse or chance fractures of the spine: the seat belt fracture. Am J Radiol 3: 844-849.

19 Skold G, Voigt GE (1977) Spinal injuries in belt-wearing car occupants killed by head-on collisions. Injury 9: $151-161$.

20 Steckler RM, Epstein JA, Epstein BS (1969) Seat belt trauma to the lumbar spine: an unusual manifestation of the seat belt syndrome. J Trauma 9: 508-513.

21 Stevenson JH (1978) Severe thoracic intra-abdominal and vertebral injury occurring in combination in a patient wearing a seat belt. Injury 10: 321-323.

22 Taylor GA, Dunne EK (1988) Lap-belt injuries of the lumbar spine in children: a pitfall in CT diagnosis. Am J Radiol 150: 1355-1358.

23 Howland WJ, Curry JL, Buffington CB (1965) Fulcrum fractures of the lumbar spine. JAMA 193: $240-241$.

24 Smith WS, Kaufer H (1969) Patterns and mechanisms of lumbar injuries associated with lap seat belts. J Bone Joint Surg 51-A: 239-254.

25 Blasier RD, LaMont RL (1985) Chance fracture in a child: a case report with nonoperative treatment. J Pediatr Orthop 5: 92-93.

26 Gallagher DJ, Heinrich SD (1990) Pediatric chance fracture. J Orthop Trauma 4: 183-187.

27 Hope PG, Houghton GR (1986) Spinal and abdominal injury in an infant due to the incorrect use of a car seat belt. Injury 17: 368-369.

28 Moskowitz A (1989) Lumbar seatbelt injury in a child: case report. J Trauma 29: 1279-1282.

29 Johnson DL, Falci S (1990) The diagnosis and treatment of pediatric lumbar spine injuries caused by rear seat lap belts. Neurosurgery 26: 434-441.

30 Reid AB, Letts RM, Black GB (1990) Pediatric chance fractures: association with intra-abdominal injuries and seatbelt use. J Trauma 30: 384-391.

31 Garret JW, Braunstein PW (1962) The seat belt syndrome. J Trauma 2: 220-238.

32 Anderson PA, Rirara FP, Maier RV, Drake C (1991) The epidemiology of seatbelt-associated injuries. J Trauma 31: 60-67.

33 Gumley G, Taylor TKF, Ryan MD (1982) Distraction fractures of the lumbar spine. J Bone Joint Surg 64-B: $520-525$.

34 Green DA, Green NE, Spengler DM, Devito DP (1991) Flexion-distraction injuries to the lumbar spine associated with abdominal injuries. J Spinal Disord 4: 312-318.

35 LeGay DA, Petrie DP, Alexander DI (1990) Flexion-distraction injuries of the lumbar spine and associated abdominal trauma. J Trauma 30: 436-444.

36 Dehner JR (1971) Seatbelt injuries of the spine and abdomen. Am J Radiol 3: 833-843. 
37 Yu WY, Siu CM (1989) Seat belt injuries of the lumbar spine-stable or unstable? Paraplegia 27: 450-456.

38 Gertzbein SD, Court-Brown CM (1988) Flexion-distraction injuries of the lumbar spine. CORR 227: 52-60.

39 Gertzbein SD, Court-Brown CM (1989) Rationale for the management of flexion-distraction injuries of the thoracolumbar spine based on a new classification. J Spinal Disord 2: 176-183.

40 Huelke DF, Kaufer H (1975) Vertebral column injuries and seat belts. J Trauma 15: 304-318. 